\title{
A combined tie-fastening method for the reusable surgical gown with two neck tie belts to improve wearing comfort
}

\section{Kai-Hui Chang}

Ditmanson Medical Foundation Chia-Yi Christian Hospital

\section{Yu-Ling Chen}

Ditmanson Medical Foundation Chia-Yi Christian Hospital

Shu-Yi Dai ( $\nabla$ cych7215@gmail.com )

Ditmanson Medical Foundation Chia-Yi Christian Hospital

\section{Research note}

Keywords: combined tie-fastening, neck tie, reusable, surgical gown, $x$-ray protective apron

Posted Date: August 31st, 2020

DOI: https://doi.org/10.21203/rs.3.rs-62313/v1

License: (1) This work is licensed under a Creative Commons Attribution 4.0 International License.

Read Full License

Version of Record: A version of this preprint was published at Nursing Reports on November 16th, 2020. See the published version at https://doi.org/10.3390/nursrep10020011. 


\section{Abstract}

Objective The reusable surgical gowns made of slippery materials have the tendency to slip down as they are being worn. The rear neck tie(s) can sometimes loosen, and this would cause the surgical gown to slip down somewhat, making the medical staff feel uncomfortable. To fasten the neck ties of the surgical gown with 2 neck tie belts, we proposed a simplified method of fastening the 2 sets of tie belts together as one tie, instead of fastening them separately. We evaluated this combined tying method for its ability to secure the gown and its wearing comfort.

Results We found that combined tying tends to loosen more than separate tying after vigorous upper extremities exercise. But, for wearing comfort during the actual performance of the surgeries, the combined tying method was significantly better than the separate tying method. As a result, for reusable surgical gowns that have 2 rear neck ties, we suggest the 2 sets of rear neck ties could be fastened together as one combined tie. With this, tying could be performed easier and faster, and wearing comfort could be improved.

\section{Introduction}

The wearing of a sterile surgical gown by perioperative specialists prior to and during major surgeries is an important routine. ${ }^{1,2}$ For this purpose, use of a disposable surgical gown is convenient and popular. However, many institutions still mainly use reusable surgical gowns for their surgeries for various reasons. ${ }^{3,4}$ Waterproof or water-resistance material is one of the materials commonly used for reusable surgical gowns. These cloth materials give the gown a smooth surface, which makes them slippery. So, when someone wears a gown made of a slippery cloth, that gown has a tendency to slip along or down from his/her shoulders.

The rear neck tie(s) and rear waist tie of the reusable gown are designed as belts to be fastened, to allow the gown to wrap around the body, mainly the upper limbs and anterior chest, for a sterile outer surface. The tie belts should be fastened with the aid of a circulating nurse. The rear waist belt, at the waist-level, is used mainly to enwrap the medical staff. The rear neck tie(s) also can be used to enwrap the body, as they are often designed as inner and outer ties on the reusable gown (Fig. 1a-c). In addition, they play an important role in keeping the gown from slipping down.

Surgical gowns made of slippery materials have the tendency to slip down due to gravity and physical movements as they are being worn. The rear neck tie(s) can sometimes loosen (Fig. 1d), and this would cause the surgical gown to slip down more, making the medical staff feel uncomfortable.

Medical staff at our institute who wear slippery water-resistance reusable surgical gowns often complain that the rear neck ties loosen and the surgical gown slips down. To fasten the neck ties of the surgical gown with 2 neck tie belts, some circulating nurses have adopted a simplified method of fastening the 2 sets of tie belts together as one tie, instead of fastening them separately, in order to facilitate the wearing procedure and avoid the ties loosening (Fig. 1e). This method mimics the tying of a surgical gown with 
only one set of rear neck tie belts. In this study, we evaluated this combined tying method for its ability to secure the gown and its wearing comfort.

\section{Materials And Methods}

This study was approved by Institutional Review Board of our institute. We designed a study to test the rear neck tie loosening of the separated tie and combined tie methods. We enrolled 5 volunteers ( 3 males, 2 females) who had at least a 5-year working experience in the operating room with a gown-wearing technique as their routine practice. We aimed to evaluate the tie loosening condition of the reusable surgical gowns with 2 sets of rear neck tie belts after a series of upper limb motion exercises. Each tying method was tested 4 times with all volunteers, and also tested when wearing and not wearing the x-ray protective apron beneath the gown. All the ties were fastened with a tightening force reaching $1 \mathrm{~kg}$, as measured by a weighing device. Then, the volunteers performed 100 rounds of bilateral upper arm horizontal abduction and adduction motions. We evaluated tie loosening after the exercises by evaluating the amount of uppermost rear neck cloth edge separation, which was recorded before and after the exercise (Fig. 1f).

We also evaluated the wearing comfort of the operating surgeons. Five surgeons were selected for evaluation, and they had different specialties, including hand surgery, foot and ankle surgery, sports arthroscopy, pediatric orthopedics, and orthopedic trauma. A single scrub nurse was involved in the study, but the circulating nurses were not. The scrub nurse (observer) made observations and did the recording. These 2 tying methods could both be seen in our institution. The involved scrub nurse recorded the results by asking the surgeons: 1 . Was there any increased wearing discomfort due to the rear neck tie(s) during surgery? 2. Was there any feeling of the rear neck tie loosening at the end of surgery before they took off their surgical gowns? Also, any asking for retying of the rear neck ties during surgery or obvious tie loosening at the end of surgery was recorded. Results were recorded as the surgeons performed their specialty surgeries. Also the results of 4 consecutive times, respectively, of wearing and not wearing the $x-$ ray protective aprons underneath the gown were recorded for each surgeon.

\section{Data management and statistical analysis}

Data were presented as mean and standard deviation for continuous variables. The chi-square test was used for discrete variables to compare the differences between the 2 groups, and Student's t-test was used to compare continuous variables. A p-value $<0.05$ was considered statistically significant.

\section{Results}

To evaluate surgical gown rear neck ties loosening after exercise, 20 values were obtained for each group with ties separately or together, and with or without wearing an x-ray protective apron inside the surgical gown. The separated distance of the rear neck gown cloth is shown in Table 1. Also, the comfort evaluation of the 2 different tying methods is shown in Table 2. All surgeries proceeded following the 
usual routine and were performed smoothly without interference by the evaluations; there were no perioperative complications.

Table 1

Comparison of tie loosening by measurement of the rear gown cloth separation after exercise

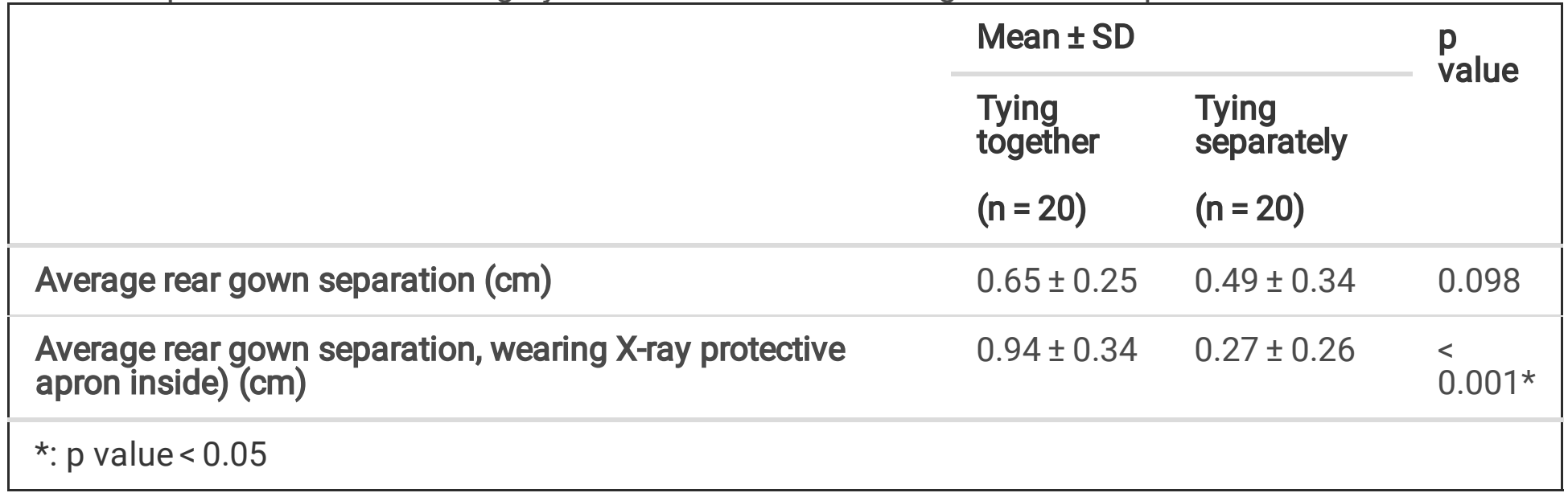

Table 2

Surgeons' responses to different tying methods

\begin{tabular}{|c|c|c|c|c|c|c|}
\hline & $\begin{array}{l}\text { Tying } \\
\text { together } \\
(n=20)\end{array}$ & $\begin{array}{l}\text { Tying } \\
\text { separately } \\
(n=20)\end{array}$ & $\begin{array}{l}\mathrm{p} \\
\text { value }\end{array}$ & $\begin{array}{l}\text { Tying } \\
\text { together } \\
\text { (with apron) } \\
(\mathbf{n = 2 0 )}\end{array}$ & $\begin{array}{l}\text { Tying } \\
\text { separately } \\
\text { (with } \\
\text { apron) } \\
(n=20)\end{array}$ & $\begin{array}{l}\mathbf{p} \\
\text { value }\end{array}$ \\
\hline $\begin{array}{l}\text { Average operation time } \\
\text { (hour) }\end{array}$ & $\begin{array}{l}1.9 \pm \\
1.0\end{array}$ & $1.8 \pm 0.6$ & 0.502 & $1.8 \pm 0.6$ & $1.6 \pm 0.5$ & 0.788 \\
\hline $\begin{array}{l}\text { Surgeon felt increased } \\
\text { discomfort during surgery }\end{array}$ & 0 & 7 & $0.008^{*}$ & 1 & 3 & 0.55 \\
\hline Rear neck tie(s) loosening & 0 & 6 & $0.02 *$ & 3 & 5 & 0.27 \\
\hline $\begin{array}{l}\text { Surgeon asking for retying } \\
\text { during surgery }\end{array}$ & 0 & 1 & 1.0 & 0 & 0 & - \\
\hline
\end{tabular}

\section{Discussion}

In this study, we found that combined tying tends to loosen more than separate tying after upper extremities exercise. But, for wearing comfort during the actual performance of the surgeries, the combined tying method was significantly better than the separate tying method. The wearing comfort results were compatible with the observed reality, in that, some medical staff in our institute changed the separated ties into combined ties to improve wearing comfort in their daily practice. 
When the surgical gown is worn, it may slip down if it is not securely wrapped around the body. The medical staff will feel discomfort when it is halfway slipping down. The rear neck tie(s) of the reusable surgical gown are meant to secure the gown to appropriately fit the surgeon. But if the tie(s) are not secured, they could loosen over time, especially as the body motions of the staff wearing the gown increase. Also, the slippery material of the surgical gown would more likely lead to ties loosening due to the gown's tendency to slip down on the staff's body.

With the reusable surgical gown with 2 rear neck ties, there is a possible reason for wearing discomfort when the 2 sets of tie belts are tightened under different degrees of tightness in order to pull the gown closer. From the outside, it looks as though the staff's back side is well-covered with the surgical gown. But actually, the upper part of the gown was secured and supported by only one set of rear neck ties which is the tighter one. The other set of ties does not contribute to securing and supporting the gown. Discomfort may result from the uneven tightening of the tie belts on the rear of the neck. In addition, the tie may loosen over time, so that the tightness of the tie belts differs more obviously, thereby causing more discomfort (Fig. 1g).

However, the combined ties distribute the pulling strength equally onto each tie belt, and the staff wearing the gown might feel better than when each tie belt has a different pulling strength. In our after-exercise test, the combined ties showed a higher likelihood of loosening, but wearing comfort was still better than that with separate ties. This may also be because the pulling strength was equally distributed on each rear neck tie belt as they loosened over time. Also, body movement during surgery is not as extreme as during our testing exercises, so the tendency to loosen during surgery would be minimized.

Loosening tended to be more significant after exercise while wearing an x-ray protective apron underneath. But for the discomfort evaluation, there was no significant difference after surgery for staff wearing an x-ray protective apron. The main reason for this is that the greater discomfort is related to the wearing of a heavy apron, which tends to minimize the discomfort from the surgical gown.

Another advantage to the combined ties is that they could facilitate wearing and taking off the gowns. The ease in the wearing procedures would be more specific to the newly trained circulating nurse. In other words, when they are handling the 2 neck ties one by one, if the tying is not smooth, he or she will be embarrassed or even afraid of not doing well. So, tying the 2 neck ties together would be a help. Shortening the time of body contact and increasing the ease of performance would allow the newly trained circulating nurse to feel more comfortable and build up confidence.

For reusable surgical gowns that have 2 rear neck ties with a tendency of loosening and allowing the gowns to slip down, we suggest fastening the 2 sets of rear neck ties together as one combined set of ties to mimic gowns with only one set of rear neck tie belts. With this, tying could be performed easier and faster, and wearing comfort could be improved for medical staffs.

\section{Limitations}


A limitation of this study is that we tested only one kind of surgical gown, which is used in our institution. No other surgical gowns with different materials were tested. Also, the times of evaluations were not many. The comfort evaluation was performed only for the surgeons and for surgeries of no more than 3 hours, which could also be the weakness of this study.

\section{Declarations}

\section{Ethics approval and consent to participate}

This study was approved by the ethics committee of our institution. (IRB number: CYCH-IRB No. 2020021). A written consent was obtained by all participants who participated in this study.

\section{Consent to publish}

Not applicable.

\section{Availability of data and materials}

The datasets used and/or analyzed during the current study are available from the corresponding author on reasonable request.

\section{Competing interests}

The authors declare that they have no competing interests.

\section{Funding}

none

\section{Authors' Contributions}

KHC and YLC drafted the manuscript. YLC and SYD performed the statistical analysis. KHC and SYD contributed to conceiving and designing the study and critically revised the manuscript. All authors read and approved the final manuscript.

\section{Acknowledgments}

We thank Fang-Chun Kuo from Chiayi Christian Hospital for the original artwork to illustrate the surgical technique. 


\section{References}

1. AORN Recommended Practices Committee. Recommended practices for surgical attire. AORN J. 2005;81(2):413-20.

2. Croke L. Guideline for surgical attire. AORN J. 2019;109(6):8-10.

3. Rutala WA, Weber DJ. A review of single-use and reusable gowns and drapes in health care. Infect Control Hosp Epidemiol. 2001;22(4):248-57.

4. Vozzola E, Overcash M, Griffing E. An Environmental Analysis of Reusable and Disposable Surgical Gowns. AORN J. 2020;111(3):315-25.

\section{Figures}
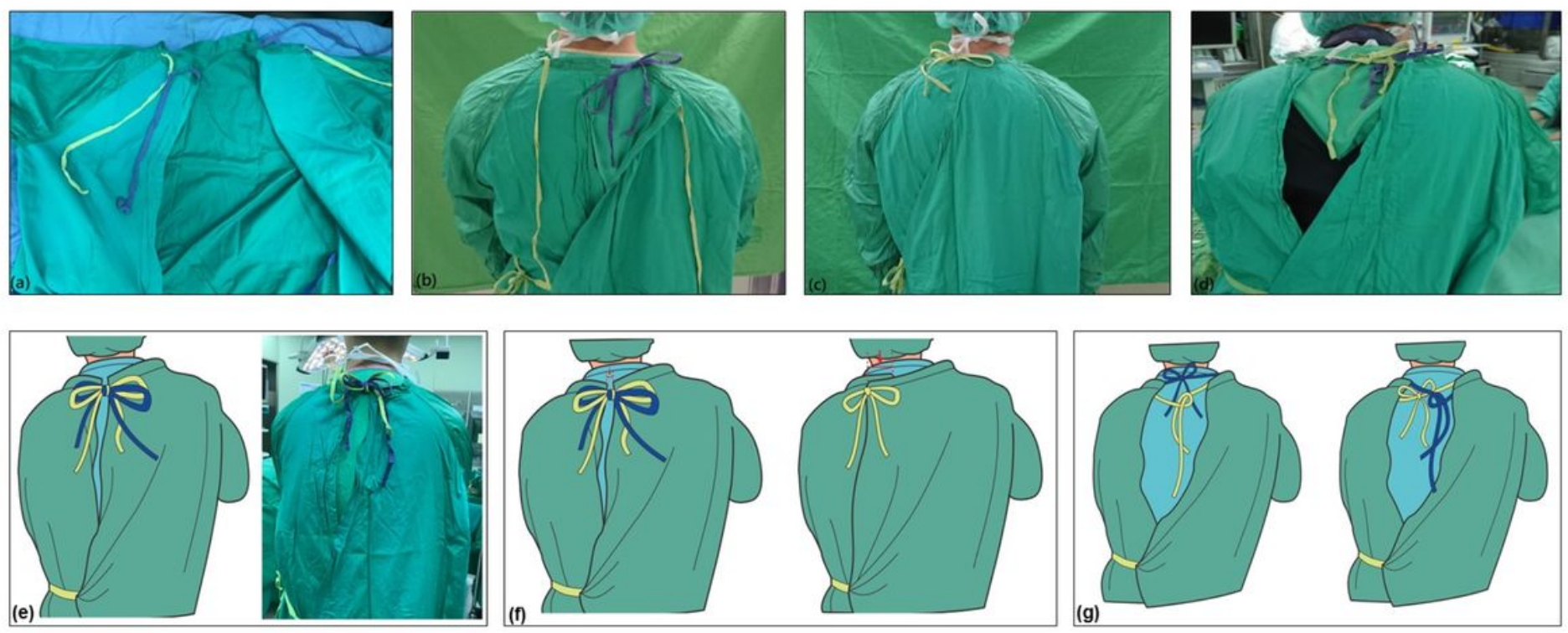

\section{Figure 1}

(a) The design of 2 sets of rear neck ties of a reusable surgical gown. (b) The inner tie fastened and (c) both ties fastened. (d) The ties loosening during surgery. (e) Illustration of the combined tie-fastening method for 2 sets of rear neck ties. (f) Schematic illustration of the measurement of the rear neck tie(s) loosening by evaluating the separation of the arrow-indicated distance before and after the exercise. $(\mathrm{g})$ Schematic illustration of the common patterns of rear neck tie loosening. 